\title{
Collaboration technology for distance learners: a needs analysis
}

\begin{abstract}
For a number of years, there have been some concern the online learning, or e-learning, especially the need for online collaboration tools to assist the students in their learning processes. This paper investigates the need for online collaboration tools for distance learners, who currently understanding their studies in a public university in a hybrid mode, which is a combination of face-to-face meetings, video conferencing sessions and the online sessions. Questionnaire was distributed to the 369 undergraduate distance learners, and the results demonstrated that the learners were moderately competent in the associated technologies in online learning. Furthermore, they had anticipated that there will be problems in performing the groupwork, which reduces their perception on online learning. This paper proposes the collaboration tools in an attempt to reduce the learners' problems and also to take full advantage of their current competencies.
\end{abstract}

Keyword: Collaboration; Online learning; Distance learning; Collaboration technology 